\title{
Clinically relevant drug interactions involving antimicrobials in a general hospital: a cross-sectional study
}

\author{
Larissa PAVANELLO $^{1}$ (D) , Fátima Goularte FARHAT ${ }^{2}$ (D), Rafaela Parolina CARVALHO ${ }^{3}$ (D), Hellen Torres GREGóRIO ${ }^{4}$ (D) \\ ${ }^{1}$ Master student at Department of Physiological Sciences of Piracicaba Dental School - Campinas University, Piracicaba, Brazil; ${ }^{2} \mathrm{Clinical}$ \\ Pharmacy autonomous consultant, Piracicaba, Brazil; ${ }^{3}$ Professor at Pharmacy Course of the Methodist University of Piracicaba and doctoral \\ student at Department of Physiological Sciences of Piracicaba Dental School - Campinas University. Piracicaba, Brazil; ${ }^{4}$ Pharmacy Department of \\ Santa Casa de Piracicaba Hospital, Piracicaba, Brazil. \\ Corresponding author: Pavanello L, laah_pavanello@hotmail.com
}

Submitted: 28-01-2021 Resubmitted: 17-05-2021 Accepted: 28-05-2021

Peer review: blind reviewers

\begin{abstract}
Objective: To assess the prevalence of pDDI involving antimicrobials and other standardized drugs in a large general hospital in the interior of São Paulo. Methods: quantitative study, with cross-sectional design and data collection by documentary analysis of hospital prescriptions from April to June 2017. Results: 66 clinically relevant pDDI were found, which corresponded to approximately $7.3 \%$ of antimicrobial prescriptions, being 93.9\% (62) contraindicated / severe and 6.1\% (4) moderate. There was no difference in the prevalence of clinically relevant pDDIs between critical and non-critical inpatient, in addition to all contraindicated interactions (10) having occurred in the clinical and surgical units. The most prevalent pDDI were, with respective degrees of documentation, between vancomycin and amikacin (47\%- reasonable), clarithromycin and simvastatin (13.6\%-good), and ciprofloxacin and simvastatin (7.6\%-good). Conclusion: For the proper prevention of potential drug-related problems, mechanisms to guarantee the quality of prescriptions by trained clinical pharmacists are of fundamental importance, in addition to alert systems and drug interaction information for the health team, then ensuring quality pharmacotherapy and patient safety.
\end{abstract}

Keywords: drug interactions; anti-infective agents; patient safety; hospital; pharmacy service.

\section{Interações medicamentosas clinicamente relevantes envolvendo antimicrobianos em um hospital geral: um estudo transversal}

\begin{abstract}
Resumo
Objetivo: investigar a prevalência de IMP envolvendo antimicrobianos e outros medicamentos padronizados em um hospital geral de grande porte do interior de São Paulo. Métodos: Foi realizado um estudo quantitativo, com delineamento transversal e coleta de dados por análise documental de prescrições hospitalares durante o período de abril a junho de 2017. Resultados: foram encontrados 66 IMP clinicamente relevantes, as quais corresponderam a aproximadamente 7,3\% das prescrições de antimicrobianos, sendo 93,9\% (62) contraindicados/graves e 6,1\% (4) moderadas. Não houve diferença na prevalência de IMP clinicamente relevantes entre as unidades de internação de pacientes críticos e não críticos, além de todas as interações contraindicadas (10) terem ocorrido nas unidades de clínica médica e cirúrgica. As IMP mais prevalentes foram, com respectivos graus de documentação, entre vancomicina e amicacina (47\%- razoável), claritromicina e sinvastatina (13,6\%-bom) e ciprofloxacina e sinvastatina (7,6\% - bom). Conclusão: é evidente a importância de mecanismos que assegurem a qualidade das prescrições para adequada prevenção de potenciais problemas relacionados a medicamentos, por farmacêuticos clínico treinados, além de sistemas de alerta e de divulgação de informações para a equipe de saúde, garantindo assim a qualidade e segurança da farmacoterapia e do paciente.
\end{abstract}

Palavras-chave: interações medicamentosas; segurança do paciente, hospital, serviço de farmácia.

\section{Introduction}

Although drugs are used to prevent, diagnose and treat diseases, they can generate drug-related problems (DRPs), which are defined as any undesirable event experienced by a patient that involves or is suspected to involve drug therapy and this, interferes potentially in its therapy. ${ }^{1}$ Therefore, it is important to note that drug-drug interactions (DDI) are recognized as a DRPs and when not identified and corrected, they can lead to relevant clinical complications. DDIs are defined as a change in the effect of a drug arising from the interaction with one or more drugs and can cause an increase or decrease in the success of pharmacotherapy. ${ }^{2}$ They are a major concern in the health area because they increase the frequency of outpatient care or length of stay, health costs and negatively impact morbidity and mortality. ${ }^{3,4}$ Consequently, resolving PRMs is essential to improve the quality of care and treatment and patient safety. ${ }^{5}$ 
The risk and severity of drug interactions depend on differents factors, including the number of drugs prescribed and duration of treatment, the patient's clinical characteristics and conditions, and the segmentation of health care to which patients are subjected. ${ }^{6}$ Therefore, as a DDI will not always generate a clinically relevant result, then the potential DDI (pDDI) is considered, defined when there is a concomitant administration of two or more drugs that can lead to a relevant result, therefore, the pDDI are of concern due to its likelihood of causing adverse drug reactions (ADRs).

Antimicrobials are among the most prescribed drugs in outpatient and inpatient settings. ${ }^{8,9}$ While the rate of use of antimicrobials in developed countries is $30 \%$, in underdeveloped countries, it is between 35 to $60 \%$, both for therapeutic or prophylactic indications, during the hospitalization period. ${ }^{9}$ It is estimated that more than $50 \%$ of the prescriptions are inadequate in the route of administration, in the dose and duration of treatment, as well as the indication of the drug., ${ }^{9,10}$ The inappropriate use of antimicrobials contributes to emergence and development of resistant organisms and, in addition, they are subject to pDDIs because they are always in association with other drugs prescribed for treatment and patient support, might leading to increased morbidity, mortality and health costs. ${ }^{9}$

Baniasadi, Farzanegan and Alehashem ${ }^{11}$ identified that antimicrobia agents represented the main pharmacological class involved in serious pDDI and contraindicated in patients seen in a cardiothoracic intensive care unit (ICU), accounting for $45.87 \%$ of these events. The same was observed by Queiroz et $a^{12}$ for whom antimicrobials were the main class involved in clinically relevant pDDI in neonatal ICUs, and by Marques et $a{ }^{13}$, who observed that antimicrobials were among the three classes of drugs with the highest prevalence of clinically significant PDDI in the ICU. Beyond them, Ziehl et $a^{14}$ identified that antimicrobials were involved in $12(23.5 \%)$ of the $51 \mathrm{pDDI}$ detected in ICU patients and a positive incremental relationship was found between number of medications, length of stay, and number of pDDI; and Kuscu et $a^{15}$ multicentric study identified that $\mathrm{pDDI}$ involving antimicrobials were present in $22.7 \%$ of hospitalized patients.

Due to the potential for drug interactions presented by the administration of antimicrobials, the risk of clinical consequences added to the patient's clinical condition (number and types of drugs prescribed, complexity of therapeutic schemes, severity of the disease), it is increasingly necessary to know the interactions and highlight those that they really relevant in the clinic, prioritizing electronic alerts (if the hospital has a computerized system) to facilitate the work of the clinical pharmacy, thus avoiding risks to patient's health due to the use of medicines.

Thus, this study aims to analyze the profile of prescriptions with antimicrobials, identifying the prevalence of clinically relevant pDDIs involving the association of antimicrobials and other drugs in a large general hospital in the interior of São Paulo state, Brazil, in its various inpatient units. It is expected to promote and emphasize the importance of hospital investments in clinical pharmacy teams and support systems for medical prescription.

\section{Methods}

Quantitative study, descriptive, with cross-sectional design and data collection by documentary analysis of hospital prescriptions, from April to June 2017. The research was carried out in a large general hospital serving adults and pediatrics with 319 beds, destined to attend the Unified Health System (70\%), health plans and private individuals in the Piracicaba region, São Paulo state, Brazil. At that time of this study, the pharmacist's team was composed of seven professionals, who were responsible for all functions of the Pharmacy Service and a scale for one of these pharmacists to participate in the multiprofessional visit at the two Adult ICU, as part of a preliminary work of clinical pharmacy. There were electronic and manual prescriptions but no one electronic pDDI alert and verification system.

This study was approved by the Research Ethics Commission ( $\mathrm{n}$. 58/2016).

The antimicrobial drugs, as well as their respective pharmaceutical forms, concentrations, and routes of administration, were identified by consulting the institution's database. Next, they were classified according to the Anatomical Therapeutic Chemical (ATC) - ATC / DDD Index (WHOCC) ${ }^{16}$, adopting the first classification level related to the anatomical groups.

The pDDI among antimicrobials and other drugs for systemic use were identified using IBM Micromedex ${ }^{\circledR}$ Drug Interactions ${ }^{17}$.

They were classified according to severity:

- Contraindicated-when drugs must not be used concurrently.

- Major - the interaction may be life-threatening and/or requires medical treatment or intervention to minimize or prevent serious adverse effects.

- Moderate- the interaction may result in an exacerbation of the patient's condition and/or requires a change in therapy.

- Minor - the interaction would have limited clinical effects, and the manifestations may include an increase in the frequency or severity of side effects, but it usually does not require a change in therapy.

And according to the degree of documentation, which considers the quality of the existing scientific evidence, suggested by Micromedex ${ }^{\circledR}$ Drug Interaction ${ }^{17}$ database:

- Excellent - when controlled studies established the existence of the interaction.

- Good-when strong documentation suggests the existence of an interaction, but well-controlled studies are lacking.

- Reasonable-when the available documentation is scarce, but the pharmacological bases make it possible to suspect the interaction.

- Poor-when documentation is limited to case studies.

- Improbable - when documentation is poor and pharmacological bases are lacking.

- Unknown- when the documentation about the interaction is not known.

For the purposes of this study, contraindicated, major and moderate pDDIs with at least a reasonable degree of documentation were considered of clinical relevance.

To calculate the prevalence of pDDI, the total number of prescriptions - manual and electronic - from all inpatient units served by the Pharmacy Service was analyzed one fixed day a week for 10 weeks, from April to June 2017. Thus, all prescriptions of Adult ICU, Emergency Care ICU (EC- ICU), Unit Coronary (CCU), Pediatric ICU, and Clinical, Surgical and Pediatric wards were analyzed during this period. The patients admitted to EC-ICU correspond to those who are just waiting for a bed in the Adult ICU and, therefore, were considered critical patients in addition to these for the present analysis. 
The results were displayed in tables and figures for a better description of the prevalence and relevance of pDDI in the different inpatients units, including critical and non-critical ones.

To check the chance of prescribing antimicrobials, as well as the occurrence of pDDI, to be associated with the unit of hospitalization, Odds-Ratio with a 95\% confidence interval (Cl) was calculated, followed by the Chi-square, considering statistically significant $p$ values $<0.05$, with the help of the Bioestat 5.3 program.

\section{Results}

The total of 2,486 prescriptions were analyzed in the period, of which 904 (36.4\%) contained at least one antimicrobial.

Throughout the period, $88 \mathrm{pDDI}$ were identified, of which 10 (11.4\%) contraindicated, 52 (59.1\%) major, 4 (4.5\%) moderate and $22(25 \%)$ minor. When the severity was assessed together with the recommendation degree of the documentation, 66 pDDI (75\%) were classified as clinically relevant, with $93.9 \%$ (62) contraindicated / major and 6.1\% (4) moderate. Thus, approximately $7.3 \%$ of antimicrobial prescriptions have presented clinically relevant pDDI. The number of prescriptions, as well as the pDDI and characteristics regarding the severity and degree of evidence of the documentation, can be seen in Figure 1.
Table 1 shows the prevalence of prescriptions containing antimicrobials and clinically relevant pDDI in the inpatient units.

In an attempt to assess the chance of inpatient units (IU) being significantly involved in the prevalence of prescriptions for antimicrobials and identified pDDI, Table 2 shows the result of the proportions test - Odds-Ratio (OR), with $95 \% \mathrm{Cl}$ - followed by calculating the Chi-Square, with $\mathrm{p}<0.05$ for statistical significance. There was a significant relationship between inpatient units and the prevalence of prescriptions with antimicrobials, being higher in critical care units, especially in the Adult/EC -ICUs and Pediatric ICU. Already among the non-critical patients, Clinical and Surgical wards presented the higher antimicrobials prevalence. However, the same was not observed when considering the prevalence of pDDI involving these drugs. This was similar between critical and non-critical patients, among critical patients from different ICUs and between clinical and surgical patients, being significantly higher only when comparing the prescriptions of the Clinical with those of the Pediatric unit $(p=0.03)$.

Next, the antimicrobial drugs involved in the respective clinically relevant pDDI during the study period are identified. During this period, 56 antimicrobial drugs were available for systemic use in the institution, belonging to the therapeutic groups: antibacterial, antimycotic, antimycobacterial and antiviral. Of these, 13 drugs (19.7\%) were involved in the clinically relevant pDDI, which are described in Table 2.

Figure 1: Number of prescriptions evaluated and pDDI identified, with severity and degree of documentation according to IBM Micromedex ${ }^{\circledR}$ Drug Interaction

Total prescriptions analyzed
$\begin{gathered}\text { Prescriptions containing } \\ \text { antimicrobials }\end{gathered}$
pDDI involving antimicrobials
Severity of the pDDI (n)
according to Micromedex ${ }^{\oplus}(\mathrm{n})$

Table 1: Prevalence of prescription containing antimicrobials and clinically relevant pDDI per inpatient unit.

\begin{tabular}{|c|c|c|c|c|c|c|c|}
\hline \multirow[t]{2}{*}{ Inpatient Unit } & \multirow[t]{2}{*}{ Prescriptions } & \multicolumn{2}{|c|}{ Prescriptions containing antimicrobials } & \multicolumn{4}{|c|}{ Clinical relevance of pDDI involving antimicrobials } \\
\hline & & $\mathrm{N}$ & $\%$ & $\mathrm{Cl}$ & $\mathrm{S}$ & $\mathrm{M}$ & Total \\
\hline Adult ICU & 252 & 126 & 50,0 & - & 15 & - & 15 \\
\hline EC-ICU & 177 & 79 & 44,6 & - & 7 & - & 7 \\
\hline Pediatric ICU & 178 & 79 & 44,4 & - & 3 & - & 3 \\
\hline $\mathrm{CCU}$ & 100 & 20 & 20,0 & - & 1 & - & 1 \\
\hline Clinical & 764 & 310 & 40,6 & 3 & 19 & 4 & 26 \\
\hline Surgical & 622 & 198 & 31,8 & 7 & 6 & - & 13 \\
\hline Pediatric & 393 & 92 & $23,4 \%$ & - & 1 & - & 1 \\
\hline Total & 2486 & 904 & 36,4 & $\begin{array}{l}10 \\
(15,1 \%)\end{array}$ & $\begin{array}{l}52 \\
(78,8 \%)\end{array}$ & $\begin{array}{l}4 \\
(6,1 \%)\end{array}$ & $\begin{array}{l}66 \\
(7,3 \%)\end{array}$ \\
\hline
\end{tabular}

$\mathrm{Cl}$ : Contraindicated; S: Major; M: Moderate.

ICU: Intensive Care Unit; EC-ICU: Emergency Care ICU; CCU: Unit Coronary. 
The results show that glycopeptide (vancomycin) with aminoglycosides represented the highest prevalence of pDDI during the study $(50.0 \%, 33)$ - been amikacin $(47.0 \%, 31)$ and gentamicin $(3.0 \%, 2)$ - and $63.5 \%$ of the 52 pDDI classified as major.

In the sequence, with the second highest prevalence of pDDI, is the macrolide clarithromycin $(24.2 \%, 16)$. All interactions described with this drug had occurred in non-critical patients, have a good to excellent degree of evidence and responded for $90 \%$ (9) of contraindicated, $7.7 \%$ (4) of major and $75 \%$ (3) of moderate pDDI identified, with risk to put patient's life at danger due to serious adverse reactions.

The third highest prevalence of pDDI involved the fluoroquinolone ciprofloxacin $(10.6 \%, 7)$, which also occurred in non-critical patients and represented $13.5 \%$ (7) of the major pDDI, with at least reasonable degree of evidence.

Figure 2 summarizes the groups of drugs involved in $\mathrm{pDDI}$ with antimicrobials through the ATC Classification, level 1 , and it is possible to notice the higher prevalence of interactions between Antiinfectives for systemic use, followed by Cardiovascular System and Blood and Hematopoietic Organ, which are related to the chronic treatment of inpatients comorbidities, especially in the Clinical and Surgical units.

Associations of Anti-infective accounted for $51.5 \%$ (34) of the identified pDDI, mainly explained by the association between vancomycin and amikacin (31). The non-antimicrobial drugs that individually presented a higher prevalence of $\mathrm{pDDI}$ with antimicrobials were simvastatin $(22.7 \%, 15$, C-Cardiovascular System) and warfarin (10.6\%, 7, S- Blood and Hematopoietic Organs).

In the present study, pDDI with simvastatin occurred when it was associated with macrolide antimicrobials - clarithromycin (9) and azithromycin (1), and to the fluoroquinolone group - ciprofloxacin (5). On the other hand, pDDIs involving the combination of warfarin and antimicrobials occurred when used concomitantly with penicillins- piperacillin + tazobactam (3) and oxacillin (1); macrolides - clarithromycin (2), and fluoroquinolones- ciprofloxacin (1).

Table 2: Analysis of the relationship between inpatient units and the prevalence of antimicrobials prescription and clinically relevant pDDI.

\begin{tabular}{|c|c|c|c|c|c|c|c|c|}
\hline \multirow[t]{2}{*}{ Variables } & \multicolumn{2}{|c|}{$\begin{array}{l}\text { Prescriptions containing } \\
\text { antimicrobials }\end{array}$} & \multirow[t]{2}{*}{ OR (Cl 95\%) } & \multirow[t]{2}{*}{$\mathbf{P}$} & \multicolumn{2}{|c|}{$\begin{array}{l}\text { Clinical relevant pDDI } \\
\text { involving antimicrobials }\end{array}$} & \multirow[t]{2}{*}{ OR (Cl 95\%) } & \multirow[t]{2}{*}{$\mathbf{P}$} \\
\hline & Yes & No & & & Yes & No & & \\
\hline \multicolumn{9}{|l|}{ Patient Criticality } \\
\hline \multirow{2}{*}{$\begin{array}{l}\text { Critical } \\
\text { Non-critical }\end{array}$} & 304 & 403 & $1.48(1.24-1.77)$ & $<0.0001^{*}$ & 26 & 278 & $1.31(0.78-2.19)$ & 0.37 \\
\hline & 600 & 1178 & & & 40 & 560 & & \\
\hline \multicolumn{9}{|l|}{ Critical patient profile } \\
\hline Adult ICU + EC-ICU ( & 205 & 224 & & & 22 & 183 & & \\
\hline Pediatric ICU $(\bullet)$ & 79 & 99 & & & 3 & 76 & & \\
\hline $\operatorname{CCU}(\bullet)$ & 20 & 80 & & & 1 & 19 & & \\
\hline$(\mathbf{a})(\bullet)$ & & & $1.15(0.81-1.63)$ & 0.50 & & & $3.05(0.89-10.48)$ & 0.11 \\
\hline$(\mathbf{Q})(\bullet)$ & & & $3.66(2.16-6.19)$ & $<0.0001^{*}$ & & & $2.28(0.29-17.90)$ & 0.67 \\
\hline$(\bullet)(\bullet)$ & & & $3.19(1.80-5.66)$ & $<0.0001^{*}$ & & & $0.75(0.27-2.12)$ & 0.79 \\
\hline \multicolumn{9}{|c|}{ Non-critical patient profile } \\
\hline Clinical ( $\mathbf{Q})$ & 310 & 453 & & & 26 & 284 & & \\
\hline Surgical $(\diamond)$ & 198 & 424 & & & 13 & 185 & & \\
\hline Pediatric ( $\square$ ) & 92 & 301 & & & 1 & 91 & & \\
\hline$(\Delta)(\diamond)$ & & & $1.47(1.17-1.83)$ & $0,0009 *$ & & & $1.30(0.65-2.60)$ & 0.56 \\
\hline (ه) (口) & & & $2.24(1.70-2.95)$ & $<0.0001^{*}$ & & & $8.33(1.11-62.25)$ & $0.03^{*}$ \\
\hline$(\diamond)(\square)$ & & & $1.53(1.15-2.04)$ & $0.0048^{*}$ & & & $6.39(0.82-49.64)$ & 0.08 \\
\hline
\end{tabular}

Figure 2: ATC classification (level 1- anatomical groups) of drugs involved in pDDI with antimicrobials during study period.

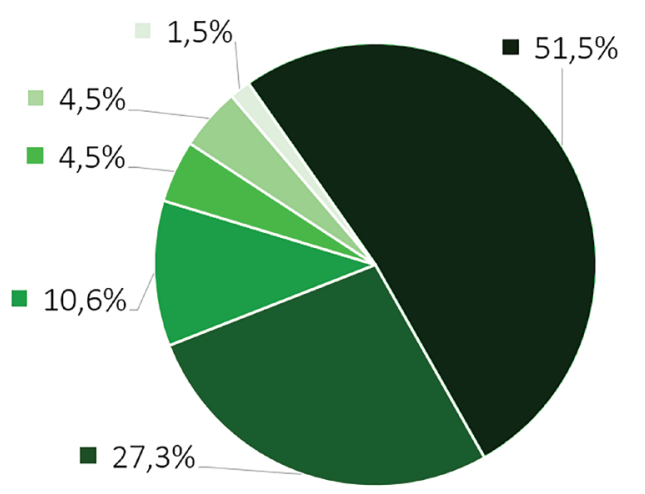

\author{
- J - Antiinfectives for systemic use \\ - C - Cardiovascular system \\ - B - Blood and blood forming organs \\ - H - Systemic hormonal preparations, excl. sex hormones and insulins \\ N - Nervous system
}

A - Alimentary tract and metabolism 
Table 3 - Description of pDDI according to severity, prevalence, inpatient unit (UI), besides degree of evidence*, potential adverse effects*, speed* and recommended clinical conduct*.

\begin{tabular}{|c|c|c|c|}
\hline \multicolumn{2}{|c|}{ Potential Drug-Drug Interaction } & \multirow{2}{*}{$\begin{array}{l}\text { N (\%) } \\
\text { IU - n }\end{array}$} & \multirow{2}{*}{$\begin{array}{l}\text { Degree of } \\
\text { evidence }\end{array}$} \\
\hline Drug A & Drug B & & \\
\hline Contraindicated & & $n=10$ & \\
\hline Clarithromycin & Simvastatin & $\begin{array}{l}9(13.6 \%) \\
\text { Clinical - } 2 \\
\text { Surgical - } 7\end{array}$ & Good \\
\hline Linezolid & Fluoxetine & $\begin{array}{l}1(1.5 \%) \\
\text { Clinical - } 1\end{array}$ & Good \\
\hline Major & & $n=52$ & \\
\hline \multirow[t]{2}{*}{ Vancomycin } & Amikacin & $\begin{array}{l}31(47.0 \%) \\
\text { Adult ICU - } 13 \\
\text { EC-ICU }-6 \\
\text { Ped ICU }-3 \\
\text { Clinical }-3 \\
\text { Surgical }-6\end{array}$ & Reasonable \\
\hline & Gentamycin & $\begin{array}{l}2(3.0 \%) \\
\text { Clinical. - } 2\end{array}$ & Reasonable \\
\hline \multirow[t]{3}{*}{ Ciprofloxacin } & Simvastatin & $\begin{array}{l}5(7.6 \%) \\
\text { Clinical - } 5\end{array}$ & Good \\
\hline & Warfarin & $\begin{array}{l}1(1.5 \%) \\
\text { Clinical - } 1\end{array}$ & Excellent \\
\hline & Amiodarone & $\begin{array}{l}1(1.5 \%) \\
\text { Clinical - } 1\end{array}$ & Reasonable \\
\hline \multirow[t]{3}{*}{ Clarithromycin } & Warfarin & $\begin{array}{l}2(3.0 \%) \\
\text { Clinical - } 2\end{array}$ & Excellent \\
\hline & Carbamazepine & $\begin{array}{l}1(1.5 \%) \\
\text { Clinical - } 1\end{array}$ & Excellent \\
\hline & Digoxin & $\begin{array}{l}1(1.5 \%) \\
\text { Clinical - } 1\end{array}$ & Excellent \\
\hline $\begin{array}{l}\text { Piperacillin+ } \\
\text { Tazobactam }\end{array}$ & Warfarin & $\begin{array}{l}3(4.5 \%) \\
\text { Adult ICU- } 2 \\
\text { CCU - } 1\end{array}$ & Good \\
\hline $\begin{array}{l}\text { Sulfamethoxazole+ } \\
\text { Trimethoprim }\end{array}$ & Amitriptyline & $\begin{array}{l}1(1.5 \%) \\
\text { Clinical - } 1\end{array}$ & Good \\
\hline Azithromycin & Simvastatin & $\begin{array}{l}1(1.5 \%) \\
\text { Clinical - } 1\end{array}$ & Good \\
\hline Isoniazid & Rifampicin & $\begin{array}{l}1(1.5 \%) \\
\text { Clinical - } 1\end{array}$ & Good \\
\hline Neomycin & Furosemide & $\begin{array}{l}1(1.5 \%) \\
E C-I C U-1\end{array}$ & Reasonable \\
\hline Oxacillin & Warfarin & $\begin{array}{l}1(1.5 \%) \\
\text { Clinical - } 1\end{array}$ & Reasonable \\
\hline Moderate & & $n=4$ & \\
\hline Clarithromycin & Prednisone & $\begin{array}{l}3(4.5 \%) \\
\text { Clinical - } 3\end{array}$ & Good \\
\hline Fluconazole & Cimetidine & $\begin{array}{l}1(1.5 \%) \\
\text { Clinical - } 1\end{array}$ & Good \\
\hline
\end{tabular}

\section{Potential adverse effect (speed1) and clinical conduct}

Myopathy and rhabdomyolysis (NS1): discontinue simvastatin during treatment or replace it with a statin that is not dependent on CYP3A4 metabolism. If concomitant therapy cannot be avoided, use the lowest possible dose of simvastatin.

Serotonin syndrome (NS1): immediate interruption of fluoxetine treatment and monitoring for syndrome serotoninergic por 5 weeks or up to 24 hours after the last dose of linezolid.

Nephrotoxicity and / or additive ototoxicity (NS1): if the concomitant therapy cannot be avoided, monitor the patient and his renal function, adjusting the dose of both if necessary.

Nephrotoxicity (NS1): monitoring of renal function

Myopathy and rhabdomyolysis (NS1): monitoring of signs and suspending concomitant use if creatinine enzyme levels show a significant increase.

Bleeding (late1): when possible, replace ciprofloxacin with another with a lower risk of bleeding (clindamycin and cephalexin). If concomitant use, monitor the INR frequently.

Cardiotoxicity due to increased QT interval (NS1): avoid concomitant use. Due to amiodarone's long T1/2, the drug interaction may occur even after discontinuation.

Bleeding (late1): when possible, replace clarithromycin with another with a lower risk of bleeding (clindamycin and cephalexin). If concomitant use, monitor the INR frequently.

Decrease in clarithromycin levels and increase in carbamazepine (fast1): consider the need to adjust the doses of one or both.

Increased toxicity of digoxin (nausea, vomiting, arrhythmias) (late1): monitoring blood concentrations of digoxin and signs of toxicity.

Bleeding (late1): when possible, replace piperacillin with another with less risk of bleeding. If concomitant use, monitor the INR frequently.

Cardiotoxicity due to increased QT interval (NS1): concomitant administration is not recommended.

Rhabdomyolysis (NS1): patient monitoring for signs and symptoms of rhabdomyolysis (dark urine, muscle pain).

Hepatotoxicity (late1): monitoring of liver function, especially in patients with risk factors.

Ototoxicity and / or additive nephrotoxicity (NS1): concomitant use should be avoided due to the risk of increased neomycin concentrations. If used, monitor for ototoxicity / nephrotoxicity.

Decreased INR / prothrombin time and anticoagulant effectivenesS (late1): concomitant use may require a 2 to 4 -fold increase in the dose of warfarin to maintain the target anticoagulation, with constant monitoring of INR / thromboplastin time.

Increased plasma concentrations of prednisone and its adverse effects (late1): dose adjustment may be necessary in concomitant treatment with clarithromycin and drugs metabolized by CYP3A4.

Decreased absorption and effectiveness of fluconazole (late1): concomitant use should be avoided. Otherwise, administer cimetidine at least two hours after fluconazole and carefully monitor the patient for antifungal effectiveness. 


\section{Discussion}

In recent years, the use of antimicrobials in hospitals has increased dramatically and more than a third of antibiotics are prescribed in disagreement with the guidelines, being a common cause of DRPs and compromising the quality and success of pharmacotherapy and patient safety. ${ }^{15}$

The prevalence of prescriptions containing antimicrobials was $36.4 \%$ (88), varying from $20 \%$ to $50 \%$ depending on the inpatient unit and being higher in the ICUs. Rodrigues and Bertoldi ${ }^{18}$ identified that $52.4 \%$ of ICU patients used at least one antimicrobial in a private hospital in Santa Maria - RS, while Alvim et $a /^{19}$ observed a prevalence of $25 \%$ among patients admitted to the ICU of a hospital in Juiz de Fora - MG, in contrast to the findings by Vicent et $a^{20}$, where $70 \%$ of patients received at least one antibiotic during hospitalization of ICU.

The prevalence of pDDI in antimicrobial prescriptions in this study was lower than that described by Piedade et $a^{21}$, in a large hospital in Jequié - BA, which found $46.5 \%$ of prescriptions for antimicrobials with some $\mathrm{pDDI}$, also computing the non-significant ones, and that Kuscu et $a{ }^{15}$, which identified $22.7 \%$. On the other hand, although the proportion of clinically relevant pDDI is lower than that found by other authors, their severity was greater than that described by them. In the present study, $75 \%$ of the identified pDDI were classified as clinically relevant, been $93.9 \%$ contraindicated / major and $6.1 \%$ moderate, while Alvim et $a{ }^{19}$ described $98.0 \%$ of the total pDDI identified as having an important and well-documented clinical value, been $51.0 \%$ contraindicated / major and $46.9 \%$ moderate; Piedade et $a^{21}$ described $80.4 \%$ of the pDDI identified as having clinical relevance, been $30.3 \%$ contraindicated / major and $49.9 \%$ moderate; and Kuscu et $a f^{15}$ described $94.1 \%$ of the pDDI with clinical relevance, been $45.8 \%$ contraindicated / major and $54.2 \%$ moderate.

The differences in institutions, profile of inpatients, protocols adopted and measures to control and monitor the prescription and use of antimicrobials can help to explain the differences found, since these authors used the same source IBM Micromede ${ }^{\circledR}$ Drug Interactions ${ }^{17}$ and format for classification of pDDI that the present study.

Moreover, Clinical and Surgical wards presented $100 \%$ of the contraindicated pDDI in the period, as well as proportions of major pDDI close to those of the critical patients. Consequently, whatever the scenario, it is evident the importance of mechanisms that ensure the quality of the prescription for the adequate prevention of potential serious and preventable adverse events in critical and non-critical patients. In addition, this predominance should alert the clinical pharmacist to the need for attention also to the pDDI that can occur after the drug reconciliation process carried out during the moment of the patient's hospitalization.

Corroborating the results of the present study, Kurcu et $a^{15}$ also found no differences in the prevalence of pDDI between critical and non-critical patients, and between clinical and surgical patients. In these units, most patients are submitted to multiple therapeutic regimes and, considering the severity presented by hospitalized patients, the probability of DDI is greater.

Such a situation reinforces the importance of clinical pharmaceutical activity both in ICU as well as in units for non-critical patients, at least with the careful pharmaceutical evaluation of the prescriptions and guiding the team as to the management and or monitoring of the patient in relation to clinically relevant pDDI. Newsome et $a^{22}$ identify that, although intensive care pharmacists are widely recognized members of the team, unlike other health care professions they do not have standardized proportions of pharmacist/patient that establish the best cost-benefit ratio and at the same time maintain the optimal patient safety. Furthermore, there is heterogeneity between their activities, with significant responsibilities in addition to direct patient care activities, with many leaderships, teaching and institutional quality improvement initiatives.

It is noteworthy that the pharmacist's intervention during prescription in critical patients was able to decrease the rate of preventable adverse events with medications by 66\%, from 10.4 to $3.5 / 1000$ patient-days $(p<0.001)$. However, a single pharmacist cannot perform all fundamental daily activities in all patients, requiring integration with other trained pharmacists and technicians, with the support of hospital administrators and others, highlighting the need for interprofessional education to enable more effective multidisciplinary teamwork. ${ }^{23,24}$

The pDDI between anti-infective for systemic use identified during the study period was higher than found by Piedade et $a^{21}$, who described $5.7 \%$ of this occurrence, related to antimicrobials for restrict use. Aminoglycosides were also pointed out as the most frequent class in pDDI involving antimicrobials, by Queiroz et $a^{12}$, and by Silva et $a^{25}$, which evaluated $\mathrm{pDDI}$ in a neonatal ICU.

The association of vancomycin glycopeptide with aminoglycosides is justified in critically ill inpatients due to synergy with staphylococci or enterococcal organisms, as a strategy to increase the effectiveness of treatment and reduce the development of bacterial resistance. ${ }^{26,27}$ In addition to the Adult-ICU, this association was also found in non-critical patients at the Surgical and Clinical wards and, therefore, requires the same clinical follow-up for signs of additive nephrotoxicity and ototoxicity.

Considering that statins are substrates for the enzymatic metabolism of cytochrome P450 (CYP450), the CYP3A4 isoenzyme, as well as antimicrobials, especially macrolides (erythromycin, clarithromycin and azithromycin), these drugs represent a significant potential for pharmacokinetic DDI, being the clinical relevance of this difficult to determine interaction. In addition, macrolides can self-stimulate their biotransformation into nitroalkanes, which form inactive CYP3A4-iron metabolite complexes, causing isoenzyme inhibition. ${ }^{28}$

Clarithromycin and erythromycin have a more pronounced inhibition of CYP3A4 and are therefore associated with an increased risk of myopathy and rhabdomyolysis by simvastatin, lovastatin and atorvastatin. In addition, they have the ability to inhibit the permeability of glycoprotein ( $\mathrm{P}$-gp) and the uptake transporter OATP1B1, which can increase serum concentrations of all statins, including those not metabolized by CYP3A4 ${ }^{28}$

On the other hand, fluvastatin and rosuvastatin are metabolized by CYP2C9, while pravastatin is not metabolized by CYP, being less susceptible to pDDI. However, Li et $a^{29}$ described that clarithromycin was able to cause an increase in adverse events also for these statins independent of CYP3A4, probably by inhibiting the transport molecules responsible for their hepatic uptake. These authors suggest that azithromycin would be less involved in adverse events caused by statins because it is not a strong inhibitor of CYP3A4 nor does it inhibit transport molecules. Helfenstein Fonseca et $a^{\beta 0}$, also describes as important, the fact that statins have high rates of binding to plasma proteins (from $80 \%$ to $>99 \%$ ), with the exception of pravastatin ( $43 \%$ to $55 \%$ ), and can be displaced from these storage sites by other drugs with greater affinity. Thus, even for statins with less potential for pharmacological interactions, risk situations can still be observed, where adequate monitoring and initial use of lower doses may be essential. 
The increased risk of myopathy and rhabdomyolysis due to the interaction of ciprofloxacin with simvastatin occurs by addition, since this quinolone is among the more than 150 drugs known to cause rhabdomyolysis, with its toxicity proportional to the time of exposure. ${ }^{32}$ Furthermore, ciprofloxacin is a weak CYP3A4 inhibitor fluoroquinolone and a substrate of P-gp and ATP1B3 which can contribute to the interaction mechanism. ${ }^{28}$

The second most important pDDI between antimicrobials and nonantimicrobials was involving warfarin. All pDDI described refer to an increased risk of bleeding, except for oxacillin and other betalactamase-resistant penicillins, which increase the metabolism of warfarin and reduce its effectiveness. The probable mechanism of pDDI that increases the risk of bleeding involves changes in the synthesis of vitamin $\mathrm{K}$ by the drugs involved.

On the other hand, the increased risk of bleeding by combining warfarin with macrolides, such as clarithromycin, is associated with a pharmacokinetic interaction by reducing the renal excretion of warfarin when associated with this class of antimicrobials. Monitoring and frequent adjustment of the anticoagulant dose are necessary at the beginning and at the end of the joint treatment with macrolides and possibly for several days after the discontinuation of this class. In contrast, the mechanism involved in the association with quinolones is unknown and it is recommended to replace the antimicrobial or at least, to constantly monitor the anticoagulant activity and possible dose adjustment of warfarin.

Adding to the context, the time for the onset of the adverse event after the occurrence of the drug interaction is, in most cases, not specified or given as late by the scientific literature. This can contribute to hamper the prompt recognition by the health team of the relationship between the adverse event and the pDDI, which increases the importance of prevention mechanisms and alerts to the health team.

Given the above, the mastery of possible DDI among medications is a necessary clinical activity in the hospital environment. Although not all DDI can be prevented, the spread of knowledge among health professionals, through the pharmaceutical professional, is one instruments for preventing DDI. Thus, leading to quality and harm-free care for the patient, besides contributing to the improvement of quality of life with regard to the optimization of pharmacotherapy and the rational use of medicines. ${ }^{32}$

The present study compared clinically relevant pDDI in different inpatients units, but it has some limitations. As a cross-sectional study, it only reported prevalence of $\mathrm{pDDI}$ in one period, but the actual occurrence of these interactions or if the clinical staff performed adequate monitoring of the patients were not investigated. Despite weekly intervals to data collection, it is possible that some prescriptions are from the same patient over time. Another limitation is the lack of data collected on the number of drugs and pDDI specifically per prescription, which would enrich the analysis.

\section{Conclusion}

pDDIs with antimicrobials are a real risk in hospital prescriptions and represent preventable and mostly serious adverse events, with sufficient evidence level of documentation. They were observed in both intensive care units and non-critical care units. In addition, they were not necessarily related to the proportion of prescriptions containing antimicrobials in the respective inpatient units. Vancomycin with amikacin, clarithromycin, and ciprofloxacin were the antimicrobials with the highest prevalence of pDDI, while simvastatin and warfarin represented the non-antimicrobial drugs. Thus, the importance of monitoring the prescription and the patient by trained clinical pharmacists is emphasized, in addition to alert and information systems for the health team. In this sense, the present work contributed to the identification, description and guidance for the management of clinically relevant pDDI involving antimicrobials, in addition to highlighting the importance of hospital support to qualification of the pharmaceutical team and electronic systems to for preventing these adverse events and, consequently, to the improve the quality of pharmacotherapy and patient safety.

\section{Funding source}

No funding was received for this work.

\section{Collaborators}

$L P$, author responsible for submitting and communicating with the journal, declare for purposes of submission to the Brazilian Journal of Pharmacy Hospitals and Health Services that the article "Clinically relevant drug interactions involving antimicrobials in a general hospital" co-authored by FGF, RPC and HTG is a complete, unabridged original article and has not been submitted to another journal. I also declare, as the author of the manuscript, that I participated in the analysis and interpretation of the data and writing of the article. I also declare that FGF participated in the conception and design, analysis and interpretation of data and writing of the article, RPC and HTG participated in the relevant critical review of the intellectual content. The final version was approved by all authors, guaranteeing the accuracy and completeness of the article.

\section{Acknowledgments}

The authors thank to the hospital staff for welcoming and helping to perform the presente study.

\section{Conflict of interest's statement}

The authors declare that there are no conflicts of interest regarding this article.

\section{References}

1. Calvo-Salazar RA, David M, Zapata-Mesa MI, et al. Drug-related problems causing hospital admissions in the emergency rooms at of high complexity hospital. Farm Hosp. 2018;42(6):228-233. DOI:10.7399/fh.10996

2. Santos TN, Macieira G, Alves BM, et al. Prevalence of clinically manifested drug interactions in hospitalized patients: A systematic review and meta-analysis. PLoS One. $2020 \mathrm{Jul}$ 1;15(7):e0235353. DOI: 10.1371/journal.pone.0235353.

3. Babelghaith SD, Wajid S, Alrabiah Z, et al. Drug-Related Problems and Pharmacist Intervention at a General Hospital in the Jazan Region, Saudi Arabia. Risk Manag Healthc Policy. 2020 May 6;(13):373-378. DOI: 10.2147/RMHP.S247686.

4. Toivo TM, Mikkola JÁ, Laine $\mathrm{K}$, et al. Identifying high risk medications causing potential drug-drug interactions in outpatients: A prescription database study based on an 
online surveillance system. Res Soc Adm Pharm. 2016 JulAug;12(4):559-68. DOI: 10.1016/j.sapharm.2015.09.004.

5. Sell R, Schaefer M. Prevalence and risk factors of drug-related problems identified in pharmacy-based medication reviews. Int J Clin Pharm. 2020 Apr;42(2):588-597. DOI: 10.1007/ s11096-020-00976-8.

6. Talebi MM, Sefidani Forough A, Riazi Esfahani P, et al. Medication Interaction and Physicians' Compliance Assessment through Medication Reconciliation Forms in a University Affiliated Hospital. Iran J Pharm Res. 2018;17(Suppl):159-167.

7. Fitzmaurice MG, Wong A, Akerberg $\mathrm{H}$, et al. Evaluation of Potential Drug-Drug Interactions in Adults in the Intensive Care Unit: A Systematic Review and Meta-Analysis. Drug Saf. 2019 Sep 5;42(9):1035-1044. DOI: 10.1007/s40264-019-00829-y.

8. Vieira PN, Vicentino Vieira SL. Uso irracional e resistência a antimicrobianos em hospitais. Arq Ciências da Saúde UNIPAR. 2018 Feb 19;21(3):209-2012. DOI: 10.25110/arqsaude.v21i3.2017.6130

9. Abdalla SN, Yousef BA. Prescribing patterns of antimicrobials in the Internal Medicine Department of Ibrahim Malik Teaching Hospital in Khartoum, 2016. Pan Afr Med J. 2019 Oct 15;34:89. DOI: 10.11604/pamj.2019.34.89.17023.

10. Onzi OS, Hoffman SP, Camargo AL. Avaliação do consumo de antimicrobianos injetáveis de um hospital privado no ano de 2009. R Bras Farm Hosp Serv Saúde São Paulo. 2011;2:20-25

11. Baniasadi S, Farzanegan B, Alehashem M. Important drug classes associated with potential drug-drug interactions in critically ill patients: highlights for cardiothoracic intensivists. Ann Intensive Care. 2015 Dec;5(1):44. doi: 10.1186/s13613-015-0086-4.

12. Queiroz KCB, Nascimento MFS, Fernandes $V$, et al. Drug Interactions on the Neonatal Prescription at ICU-HGU. UNOPAR Cient Ciênc Biol Saúde 2014;16(3):203-7. DOI: https://DOI. org/10.17921/2447-8938.2014v16n3p\%25p

13. Marques C, Leão N, Sousa, S, et al. Interações Medicamentosas na Unidade de Terapia Intensiva de um Hospital de Referência no Sul do Tocantins - Brasil. Rev Cereus. 2015;(10):3. DOI: 10.18605/2175-7275/

14. Ziehl EA, Córdova M, Fernández PB, et al. Drug-drug interactions in an intensive care unit of a tertiary hospital in southern Chile: Evaluating databases agrément. J Pharm \& Pharmacogn Res. 2019 Apr 29; 7(3), 184-192. ISSN 0719-4250

15. Kuscu F, Ulu A, Inal AS, et al. Potential Drug-Drug Interactions with Antimicrobials in Hospitalized Patients: A Multicenter Point-Prevalence Study. Med Sci Monit. 2018 jun 20;(24):4240-4247. DOI:10.12659/MSM.908589

16. World Health Oganization (WHO)/Collaborating Center for Drug Statistics Methodology. Anatomical Therapeutic Chemical classification system with Defined Daily Doses (ATC/DDD) Index. Disponivel em: <https://www.whocc.no/atc_ddd_index/>Acesso em: 2020

17. IBM Micromedex ${ }^{\circledast}$ Drug Interaction Checking [Internet database]. IBM Watson Health, Greenwood Village, Colorado, USA. Available from: <https://play.google.com/store/apps/ details? id=com.truven. druginteractionsnative.customer\&hl=pt_BR\&gl=US> Acesso em: 2020

18. Rodrigues Fd, Bertoldi AD. The profile of antimicrobial utilization in a private hospital. Cien Saude Colet. 2010 Jun;15 Suppl

\section{1:1239-47. DOI: 10.1590/s1413-81232010000700033.}

19. Alvim MM, Silva LA, Leite IC, et al. Adverse events caused by potential drug-drug interactions in an intensive care unit of a teaching hospital. Rev Bras Ter Intensiva. 2015 OctDec;27(4):353-359. DOI:10.5935/0103-507X.20150060

20. Vincent J, Sakr Y, Singer M, et al. Prevalence and Outcomes of Infection Among Patients in Intensive Care Units in 2017. JAMA. 2020; 323 (15): 1478-1487. DOI: 10.1001 / jama.2020.2717

21. Piedade DV, Silva LA, Lemos GS, et al. Potential drug interactions in medical prescriptions containing restricted use antimicrobial, for patients in a hospital within the Bahia. Medicina (Ribeirão Preto) 2015 jun8;48(3):295-307. DOI: https:// doi.org/10.11606/issn.2176-7262.v48i3p295-307

22. Newsome AS, Smith SE, Jones TW, et al. A survey of critical care pharmacists to patient ratios and pratice characteristics in intensive care units. J Am Coll Clin Pharm. 2019 Jul 23;3(1):68-74. DOI: http://DOI.wiley.com/10.1002/jac5.1163

23. Rudis $\mathrm{MI}$, Cohen $\mathrm{H}$, Cooper BE, et al. Position paper on critical care pharmacyservices. Pharmacotherapy. 2000;20(11):14001406. DOI: 10.1592/phco.20.17.1400.34893.

24. Krzyżaniak N, Pawłowska I, Pawłowski L, et al. Pharmaceutical care in the neonatal intensive care unit: Perspectives of Polish medical and pharmacy students. Currents in Pharmacy Teaching and Learning. 2019 Apr 1;11(4):361-372. https:// DOI.org/10.1016/j.cptl.2019.01.010

25. Silva UD, Soeiro CL, Resque RL, et al. Interações medicamentosas e consequentes intervenções farmacêuticas na Unidade de Terapia Intensiva de um hospital privado em Macapá, Amapá. Vigil Sanit em Debate: Soc, Ciênc \& Tecn. 2018 May 30;6(2):29. DOI:10.22239/2317-269x.00922

26. Xu Z, Xu X, Qi D, et al. Effect of aminoglycosides on the pathogenic characteristics of microbiology. Microb Pathog. 2017 Dec;113:357-364. DOI: 10.1016/j.micpath.2017.08.053.

27. Wu T, Meyer K, Harrington AT, et al. In vitro activity of oritavancin sozinho ou em combinação contra vancomicina-susceptíveis e resistant enterococci. J Antimicrob Chemother. 2019 May;74(5):1300-1305. https://DOI.org/10.1093/jac/dkz010.

28. Hylton Gravatt LA, Flurie RW, Lajthia E, et al. Clinical Guidance for Managing Statin and Antimicrobial Drug-Drug Interactions. Curr Atheroscler Rep. 2017 Oct 9;19(11):46. DOI: 10.1007/s11883-017-0682-x.

29. Li DQ, Kim R, McArthur E, et al. Risk of adverse events among older adults following co-prescription of clarithromycin and statins not metabolized by cytochrome P450 3A4. CMAJ. 2015 Feb 17;187(3):174-180. DOI: 10.1503/cmaj.140950.

30. Helfenstein Fonseca FA, Oliveira Izar MC, Bueno BSA et al. Pharmacokinetics of statins. Rev Bras Med. 2005;62(11):501-505.

31. Nieto-Ríos JF, Vega-Miranda, Serna Higuita LM. Insuficiencia renal aguda inducida por rabdomiolisis. latreia. 2016 Jun;29(2):157-169. DOI: https://DOI.org/10.17533/udea. iatreia.v29n2a05.

32. Neves $\mathrm{C}$, Colet $\mathrm{C}$. Use profile of antimicrobial and the medicine interactions in na adult ICU in Rio Grande do Sul. Rev Epidemiol e Control Infecção. 2015 Apr;5(2):65-71. DOI:10.17058/ reci.v5i2.5393. 